\title{
Resistance of passive inclined anchors in cohesionless medium
}

\author{
E. J. MURRAY and J. D. GEDDES (1989). Géotechnique 39, No. 3, 417-431
}

\section{Dr E. A. Dickin, University of Liverpool}

The Authors have presented data from an exhaustive programme of conventional model tests on inclined anchor plates including anchors in both horizontal $\left(\omega=0^{\circ}\right)$ and vertical $\left(\omega=90^{\circ}\right)$ orientations. While the Authors recognize the limitations of such small scale tests, it is of interest to draw comparisons with the centrifugal work on anchor plates at Liverpool (Dickin \& Leung 1983, Dickin 1988). The Authors' conventional uplift tests on $50.8 \mathrm{~mm}$ square plates bear close similarity to my own which were found to exceed pull-out capacities for $1 \mathrm{~m}$ square plates from centrifuge tests by $30 \%$ on average.

Few researchers have published experimental data for both vertical and horizontal anchors, thus enabling direct comparisons of respective pull-out capacities to be drawn. In Ovesen's relationship (1981) which gives the pull-out ratio

$$
P_{\omega}=90^{\circ} / P_{\omega}=0^{\circ}=0.67+1.27 \tan \phi
$$

the values for $P_{w}=90^{\circ}$ were based on his theoretical work. Fig. 14 suggests that this relationship yields lower values for the pull-out ratio than observed for shallow anchors by both myself and the Authors. The ratio appears to be considerably more dependent on embedment ratio than suggested by Ovesen's formula.

The Authors have also presented shape factors for plates with $1 / B=1$ and $L / B=2$ which seem to be independent of anchor orientation. I concluded that such shape factors are also sensibly independent of scale, and proposed an empirical expression giving the shape factor as

$$
S=1-\frac{a B}{3 L H}(6 B-7 H)
$$

where $a=1$ and $a=0.4$ for dense and loose sand respectively. Fig. 15 shows rcasonable agreement between the Author's shape factors and those derived by expression (10).

Frydman \& Shaham (1989) have suggested the following relation between shape factor, anchor geometry and embedment for anchor in dense sand

$$
S=1\left[\frac{B / L-0 \cdot 15}{1-0 \cdot 15}\right](0 \cdot 51+2 \cdot 35 \log (H / B))
$$

For square anchors, at deeper embedments in particular, equation (11) yields higher values than obtained either by the Authors or by me. However, good agreement is found for anchors with $L / B=2$.

\section{Authors' reply}

The Authors thank Dr Dickin for his contribution to our Paper. The relationship displayed in Fig. 14, between his results and those reported in the Paper, is particularly gratifying and signifi-

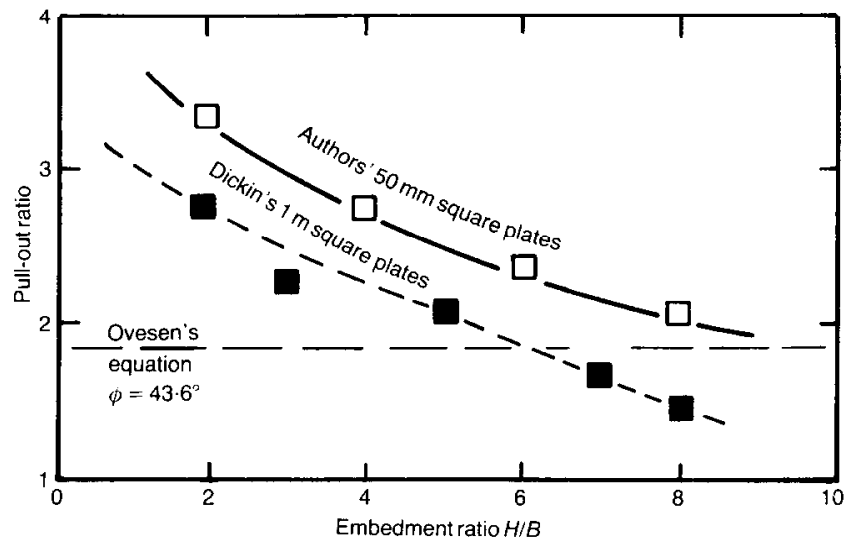

Fig. 14. Variation of pull-out ratio with embedment ratio 


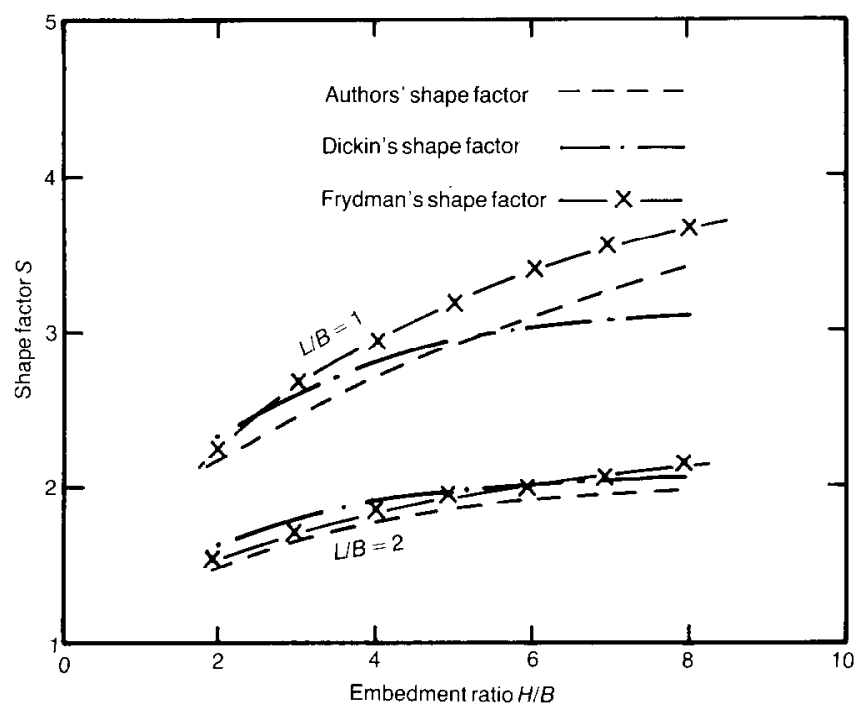

Fig. 15. Comparison between Authors' shape factors and equations (10) and (11)

cant because of the fairly close similarity, despite the considerable difference in size of the plates involved. It would appear that Ovesen's equation which gives a constant value for the pull-out ratio does not properly represent the physical facts, which clearly show a dependence on $H / B$ ratio.

The results of Fig. 15 also show encouraging similarities particularly for $L / B=2$, where the three curves can be taken as more-or-less identical. For $L / B=1$ the shape of Frydman and Shaham's curve more closely follows that of the Authors than that of Dr Dickin, though the three curves might be replaced by an averaged curve without raising too much controversy, at least for embedment ratios up to 8 .

\section{REFERENCES}

Dickin, E. A. \& Leung, C. F. (1983). Centrifugal model tests on vertical anchor plates. J. Geotech. Engng, Am. Soc. Civ. Engrs 109, No. 12, 1503-1515.

Dickin, E. A. (1988a). Uplift behaviour of horizontal anchor plates in sand. J. Geotech. Engny, Am. Soc. Civ. Engrs. 114, No. 11, 1300-1317.

Dickin, E. A. (1988b). Stress-displacement response of buried plates and pipes. Proc. Int. Conf. on Geotechnical Centrifuge Modelling, Paris, 205-214, Rotterdam: Balkema.

Frydman, S. \& Shaham, I. (1989). Pull-out capacity of slab anchors in sand. Can. Geotech. J. 26, No. 3, 385-400.

Ovesen, N. K. (1981). Centrifuge tests of the uplift capacity of anchors. Proc. 10th Int. Conf. Soil Mechs, Stockholm 2, 717-722. 